\title{
Proposed model of integrated care to improve health outcomes for individuals with multimorbidities
}

This article was published in the following Dove Press journal:

Patient Preference and Adherence

24 October 2012

Number of times this article has been viewed

Tara Sampalli

Roy A Fox

Robert Dickson

Jonathan Fox

Integrated Chronic Care Service, Primary Health Care, Capital Health, Nova Scotia, Canada
Correspondence: Tara Sampalli Integrated Chronic Care Service, Primary Health Care, Capital Health, Nova Scotia, Canada

Tel + I 9028603107

Fax + I 9028602046

Email tara.sampalli@cdha.nshealth.ca
Abstract: Multimorbidity is defined as the coexistence of multiple chronic conditions. Individuals with multimorbidity typically present with complex needs and show significant changes in their functional health and quality of life. Multimorbidity in the aging population is well recognized, but there has been limited research on ways to manage the problem effectively. More recent studies have demonstrated a high prevalence of multimorbidity in the younger demographics aged under 65 years. There is a definite need to develop models of care that can manage these individuals effectively and mitigate the impact of illness on individuals and the financial burden to the health care system. An integrated model of care has been developed and implemented in a facility in Nova Scotia that routinely treats individuals with multiple chronic conditions. This care model is designed to address the specific needs of this complex patient population, with integrated and coordinated care modules that meet the needs of the person versus the disease. The results of a pilot evaluation of this care model are also discussed.

Keywords: multimorbidities, integrated care, self-management, functional health, quality of life

\section{Introduction}

Multimorbidity has been defined as the coexistence of two or more chronic conditions in an individual. ${ }^{1}$ This problem has remained a topic of discussion and an area of research interest across the world for many years now, with little progress in the development of effective care models for individuals with such conditions. ${ }^{1-13}$ There is increasing evidence of patients with multimorbidity being encountered in primary care. ${ }^{12,14}$ The prevalence of this problem in the aging population is well recognized despite limitation in the development of effective strategies for care. ${ }^{15-17}$ More recent evidence shows an increasing trend of this problem in younger patient demographics. ${ }^{18}$ A study conducted in family practices in Canada has shown that, in approximately 900 patients, $61 \%$ in the age group 18-44 years and 93\% of those aged 45-64 years have multiple chronic conditions. The impact of multimorbidity from the patient perspective has been explored, indicating that individuals feel the current system is not addressing the basic needs of their health problems. ${ }^{19-22}$ In a study by Glynn et al, the cost implications of treating individuals with multimorbidity were explored. ${ }^{23}$ Health care utilization was examined in approximately 3000 patients in relation to the prevalence of chronic conditions. Health care utilization and cost was significantly increased among patients with multimorbidity $(P<0.001)$.

Several barriers have been identified in the literature concerning the treatment of multimorbidity, all of which make management of these patients more complex for primary care practitioners. Figure 1 demonstrates the multitude of challenges that make 
the management of multimorbidity more complex for primary care practitioners and specialists.

Patients with multimorbidity present to the health care system with unique requirements, disabilities, and functional limitations. ${ }^{21-32}$ The basic need of this population seems to be integration of care that transcends the layer of diseasespecific approaches. ${ }^{21,22}$ This integration must address the myriad disease-specific recommendations from multiple care providers, while supporting self-management strategies that can improve functionality and quality of life. The unique needs of this patient population can present a significant challenge to primary care providers who, in reality, have limited interaction time per patient per visit. ${ }^{29-32}$

Currently, the most widely referenced model for delivery of chronic disease management and prevention activities has been the chronic care model. ${ }^{25,26}$ This model includes several components, such as integration of community resources, self-management support, delivery system redesign, decision support, clinical information systems, and organizational support. The model has been used with some level of success in the management of index conditions, such as diabetes. ${ }^{27}$ However, the chronic care model does not meet all the multifaceted requirements of multimorbidity at the level of the individual. The novel care model discussed in this paper is based on concepts derived from the chronic care model in addition to concepts of relevance and importance integrated from other care models, along with some novel elements from clinical experience in treating complex patients..$^{33-46}$

\section{Multimorbidity in a clinic treating complex chronic conditions}

Challenges related to the management of multimorbidity were recognized in a treatment facility for individuals with complex diagnoses, including multiple chemical sensitivity, chronic fatigue syndrome, and fibromyalgia. The clinic receives referrals locally, nationally, and internationally. The treatment facility is located at Capital Health, Nova Scotia, and offers integrated care for individuals who have challenging and complex diagnoses or medically unexplained conditions. The multidisciplinary team of clinicians works closely with family physicians in managing the care for such individuals. The multidisciplinary team comprises physicians, nurses, occupational therapists, a psychologist, a psychotherapist, and a clinical dietitian.

The experience of the clinic is that a high percentage of patients treated have multiple chronic conditions. In reviewing 300 patients seen at the clinic, a higher percentage of females aged 45-65 years were found to have multiple chronic conditions. Only a small percentage of patients had one chronic condition in addition to the referred condition. A high percentage had two $(28 \%)$ or three $(32 \%)$ conditions in addition to the referred condition(s).

\section{Care model for treating complex conditions in the clinic}

The cornerstone of the new model for treating multimorbidity discussed in this paper was derived from the model developed for management of a complex and challenging condition, ie, multiple chemical sensitivity. ${ }^{46-48}$ Despite having a diagnosis of multiple chemical sensitivity, no two patients are prescribed the same treatment regime. ${ }^{46}$ The literature on how best to manage these patients is limited, with knowledge growing in an ad hoc manner and little or no consensus among experts across the world. In a study conducted by Sampalli et al, at least 11 different care management strategies requiring involvement of a specific cluster of health disciplines were

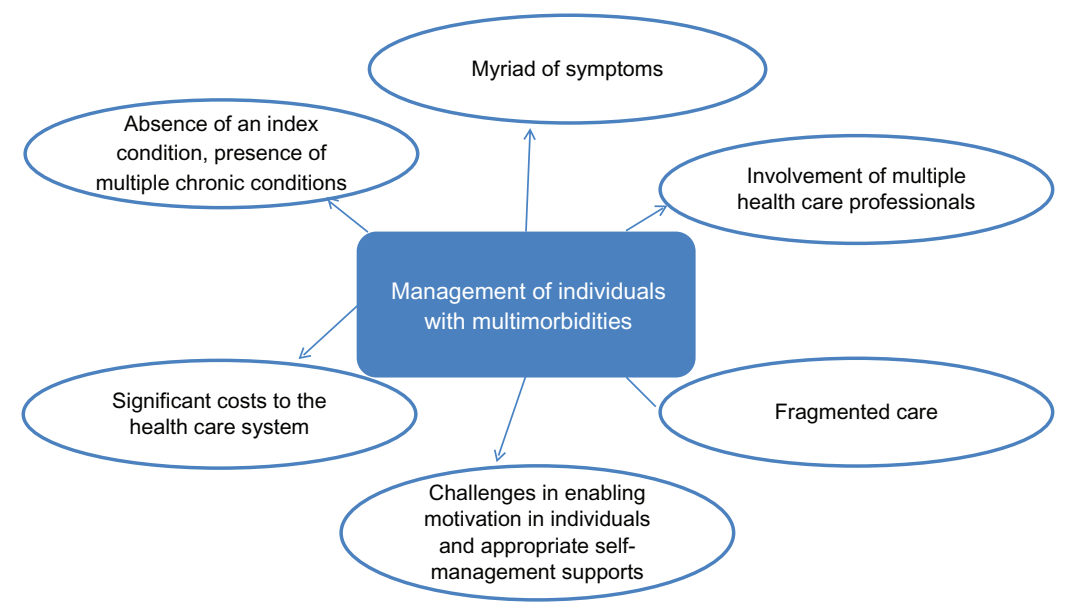

Figure I Challenges of managing multimorbidity. 
identified in 100 patients with a diagnosis of multiple chemical sensitivity. ${ }^{47}$ There were multiple variations within the care management strategies in what individuals actually received as treatment under different areas of multidisciplinary health focus. Thus, the model developed and applied for the management of multiple chemical sensitivity has a structural framework for standardizing the global elements of care deemed essential for this complex population, including a comprehensive and multidisciplinary assessment, coordination of care across multiple care providers, and interventions and education modules that are not diseasespecific but provide the flexibility for individualization of care to meet the needs of each patient. The details of this model have been discussed by the authors in another paper. ${ }^{48}$

The growing prevalence of the problem of multimorbidity in the routinely treated patient population at the clinic led to further evaluation and refinement of the existing care model. A literature review was conducted by the authors to query essential and ideal features of relevance and importance in treating individuals with multimorbidity, existing knowledge on chronic disease management models, chronic care models in Canada, care models for multiple chemical sensitivity, chronic fatigue syndrome, and fibromyalgia, and models for complex conditions. The databases reviewed included PubMed, Medline, Embase, the Cumulative Index to Nursing and Allied Health Literature, the Cochrane Central Register of Controlled Trials, and Google Scholar. MeSH headings and keywords used were "chronic care model", "chronic disease management", "patient-centered care", "integrated care", "models for multiple chemical sensitivity", "chronic fatigue syndrome", "fibromyalgia", "multimorbidities model", and "whole-person model". Over 600 articles of relevance to these topics were identified and reviewed. A summary of key features or models of importance that helped in the development of the care model for multimorbidity is presented below.

\section{Multimorbidity in the elderly}

Multimorbidity research in the elderly has outlined certain key components of care, such as comprehensive assessment, comprehensive and evidence-based care plans, supporting behaviors to improve adherence to care plans, coordination of care across primary care, specialists, hospitals, and community resources. ${ }^{15-17}$

\section{Central sensitivity syndrome}

In a review of conditions that impacted multiple systems of the body, Yunus discussed the phenomenon of central sensitization, which is a complex situation demonstrating the coexistence of multiple conditions triggered by central sensitivity. ${ }^{33}$ When researching fibromyalgia, Yunus found several complex diagnoses to overlap in individuals, such as multiple chemical sensitivity, irritable bowel syndrome, and tension-type headaches. The paradigm of central sensitivity embraces the important concept of person-centered patient care that takes into account the varying degrees of both biological and psychosocial factors in a given patient.

\section{Integrated care}

Integration of care has been a key component often discussed in relation to multimorbidity as well as complex conditions. ${ }^{34-38}$ Kodner and Spreeuwenberg defined the overall aim of integrated care as being to "enhance quality of care and quality of life, consumer satisfaction and system efficiency for patients with complex, long-term problems cutting across multiple services, providers and settings" ${ }^{35}$ Stange states that when the complexities of managing patients with chronic conditions escalate, it is important to meet and integrate the needs of the person versus the disease. ${ }^{39}$ Various studies have discussed the importance of a multidisciplinary team approach to address the physical and psychosocial concerns that can influence quality of life in individuals with chronic conditions. ${ }^{40-42} \mathrm{~A}$ few studies have emphasized the importance of the role of the team in integrating care for the person's entire constellation of comorbidities. ${ }^{43,44}$ Lastly, the importance of integrated care in improving patient empowerment and education through the provision of timely and effective selfcare support has also been discussed. ${ }^{45}$

\section{Salutogenic model}

Antonovsky and his salutogenic model for management of complex conditions was also considered in the development of the new model. ${ }^{43}$ In this model, the author identified coping mechanisms, which enabled some people to remain healthy despite unfavorable circumstances. Knowledge about predictors of positive health might be useful for health promotion activities in the general population, and also to support positive health among chronically disabled individuals. Key concepts of the salutogenic model indicate that care teams should identify and use patient self-selected health enablers in the type of treatment, education and self-management strategies applied in individualized care.

\section{Self-management amidst complexities}

Patient perspectives were gathered in a cross-sectional study conducted by Noel et al in 422 patients. ${ }^{20}$ The study results 
indicate that standardized group classes, such as Lorig's chronic disease self-management program, may not adequately address all of the concerns of patients with complex multimorbidity. ${ }^{44}$ This study showed that self-management in the areas of stress management, pain management, sleep education, sexual health, healthy eating, vocational, coping with activities of daily living, and research trends show that patients find it helpful to introduce the behavioral changes needed slowly or pace their way to the required changes. The McGill program for whole person care discusses elements of mindfulness-based stress reduction techniques to empower patients with complex diagnoses. ${ }^{45}$

\section{An integrated care model for multimorbidity}

A model of care was proposed following the literature review that integrated the key and essential features identified in the literature to revise and improve the existing care model at the clinic. An integrated phase of care by a multidisciplinary team of clinicians to address the multifaceted nature of symptoms and disease constellations in a non-disease-specific approach is the primary need of this patient population. Towards this global objective, an integrated model of care offered by a multidisciplinary care team with essential elements of care has been proposed to enable both the patient and their health care providers to establish health goals and outcomes that are not disease-specific.

The integrated care model includes essential elements of care identified in the literature, along with novel elements of relevance and importance to this particular patient population. Elements identified in the literature include a comprehensive assessment of the multifaceted diagnosis and symptom profile, evidence-based care plans, supporting behaviors to improve adherence to care plans, coordination of care across the integrated care team, primary care physicians, specialists, hospitals, and community resources. Novel elements include: a medical management scheme that facilitates the care of the patient across the spectrum of diagnoses and symptom profile; multidisciplinary care that includes rehabilitation to improve functional health and quality of life; care coordination appointments integrated into key phases of care delivery to ensure patient engagement and confidence in whole-person care and self-management; education modules that provide skills and coping strategies to help manage the needs of the person; and patient-relevant and identified self-management and behavior management supports at key phases of care delivery that are specifically designed to motivate and enhance the life skills of individuals to manage their constellation of problems better. The proposed model comprises four key phases, ie, intake, integrated care, transition, and discharge, as shown in Figure 2.

\section{Intake phase}

The aim of this phase is to gather knowledge of the individual's multifaceted needs through a comprehensive and multidisciplinary assessment. This phase of care includes an intake screen by a physician to determine the diagnostic and symptom profile of the patient. An occupational therapist reviews the care coordination and rehabilitation needs of the patient across the spectrum of care and specialists. A nurse orients and educates the individual concerning the process of care delivery in addition to gathering initial information about self-management needs. This phase of care is essential to help the care team understand the complex medical profile and individualized integration needs of the patient, in addition to educating and orienting them concerning the health care delivery format. This phase is also important in terms of identifying patient motivation and any facilitators and barriers to change. Based on the outcome of this phase, the care team will develop an individualized integrated care plan with the involvement and engagement of the patient. The overall goal of this phase is to help individuals shift from a fragmented to an integrated and non-disease-specific view of their health problems in addition to raising their self-awareness regarding the potential enablers for positive shifts in health. During this phase, the Canadian Occupational Performance Measure ${ }^{49}$ and a symptom questionnaire ${ }^{48}$ are administered to patients. The Canadian Occupational Performance Measure helps to identify and develop patientspecific health outcomes in care management.

\section{Integrated care phase}

The aim of this phase is providing treatment, education, and support for integration of the physical, functional, psychosocial, and vocational needs identified for individuals in the intake phase of care. The duration of the integrated phase can vary for individuals depending on the complexity and severity of their needs. Aspects that are reviewed regularly during this phase of integrated care include:

- functional status, symptom levels

- patient's active engagement and involvement in the care plan

- coping skills, activity, and stress management strategies and self-management skills

- education strategies

- self-management plan

- goal attainment from patient's perspective. 


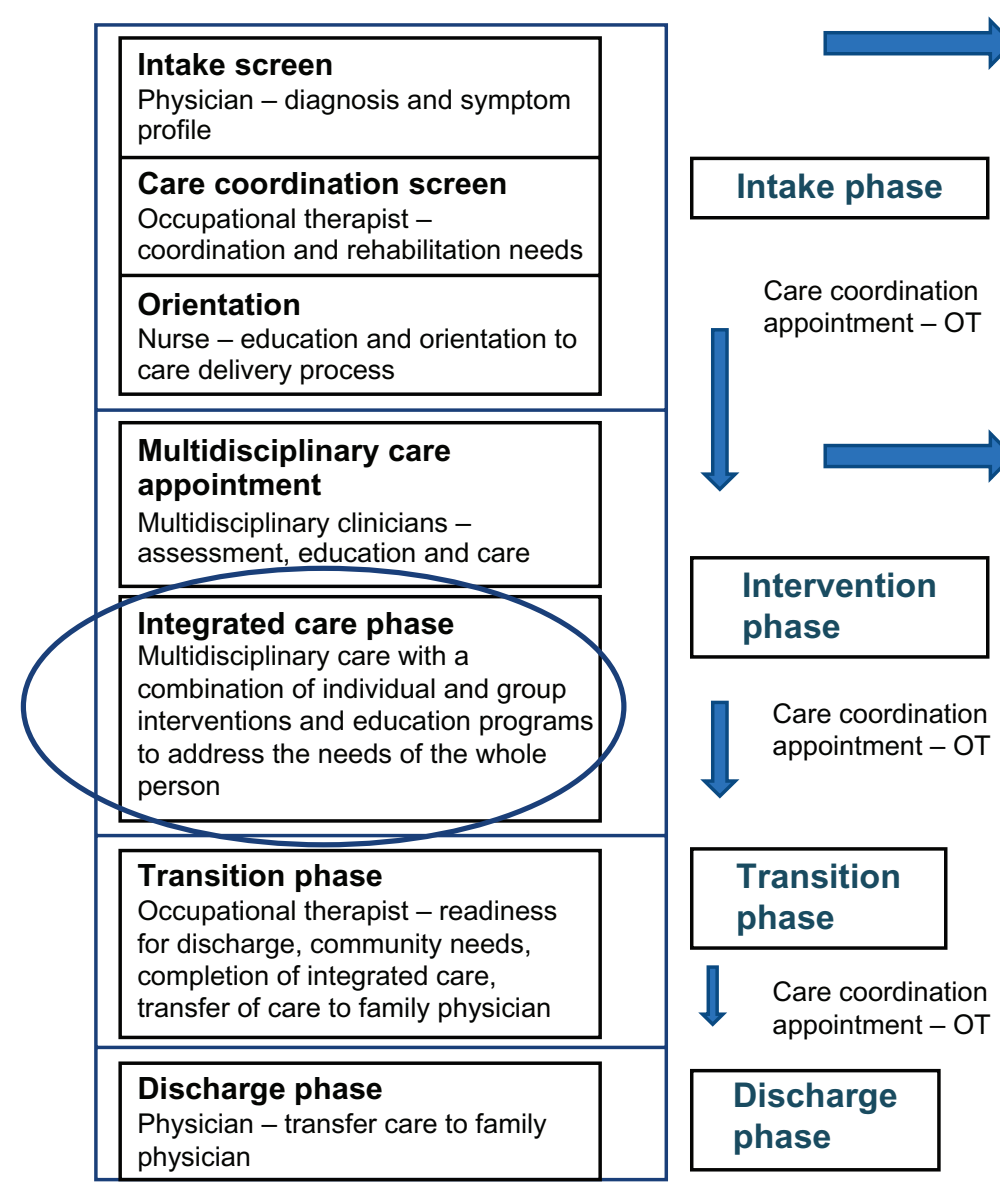

Triage 1: transfer of care to family

physician with recommendations

referral to community treatments

Outcomes: multisystem symptoms questionnaire,

Canadian occupational performance measure, Stanford chronic disease management questionnaire, SF-12 quality of life

Triage 2: transfer of care to family physician with recommendations referral to community treatments

\section{Outcomes:}

Canadian occupational performance measure, Stanford chronic disease management questionnaire, SF-12 quality of life Patient Assessment of Chronic Illness Care (PACIC)

\section{Transfer of care back to family physician}

Post discharge phone call nurse

Figure 2 Proposed model of care for multimorbidity.

Figure 3 shows details of the care modules offered in the integrated phase of care (Figure 2). Interventions offered during this phase include ongoing medical support and monitoring of disease-specific needs, dietary intervention, vocational support, functional rehabilitation, psychotherapy, and interventions for management of pain and fatigue. Coordination of care includes ongoing liaison with the patient's family physician, care providers in the community, and community wellness programs. The treatment modalities are all designed to improve overall functionality and quality of life through interventions, counseling, coaching, and education to address the needs of the individual versus treatment of the disease.

\section{Transition phase}

During this phase of care, the multidisciplinary team assesses the patient's readiness to be discharged and identifies any other pending care needs or gaps essential for the patient to self-manage their health. This phase of care delivery also involves engaging the patients in a conversation and formulating action plans around selfmanaging their condition. During this phase, the patient and the care coordinator discuss the community supports available and transfer of care to the family physician to facilitate reintegration into the community. The family physician is contacted to understand the needs of the patient at the time of transition. During the transition phase, the Patient Assessment of Chronic Illness Care questionnaire (PACIC),${ }^{50}$ Canadian Occupational Performance Measure (COPM), and symptom questionnaire are administered to patients.

\section{Discharge phase}

The discharge phase involves completion of the transition phase and final appointments that are essential to complete care for the patient. This includes a final appointment with their treating physician and a one-month post-discharge follow-up appointment with a nurse. The care of the patient is then transferred to their family physician or primary care provider. 


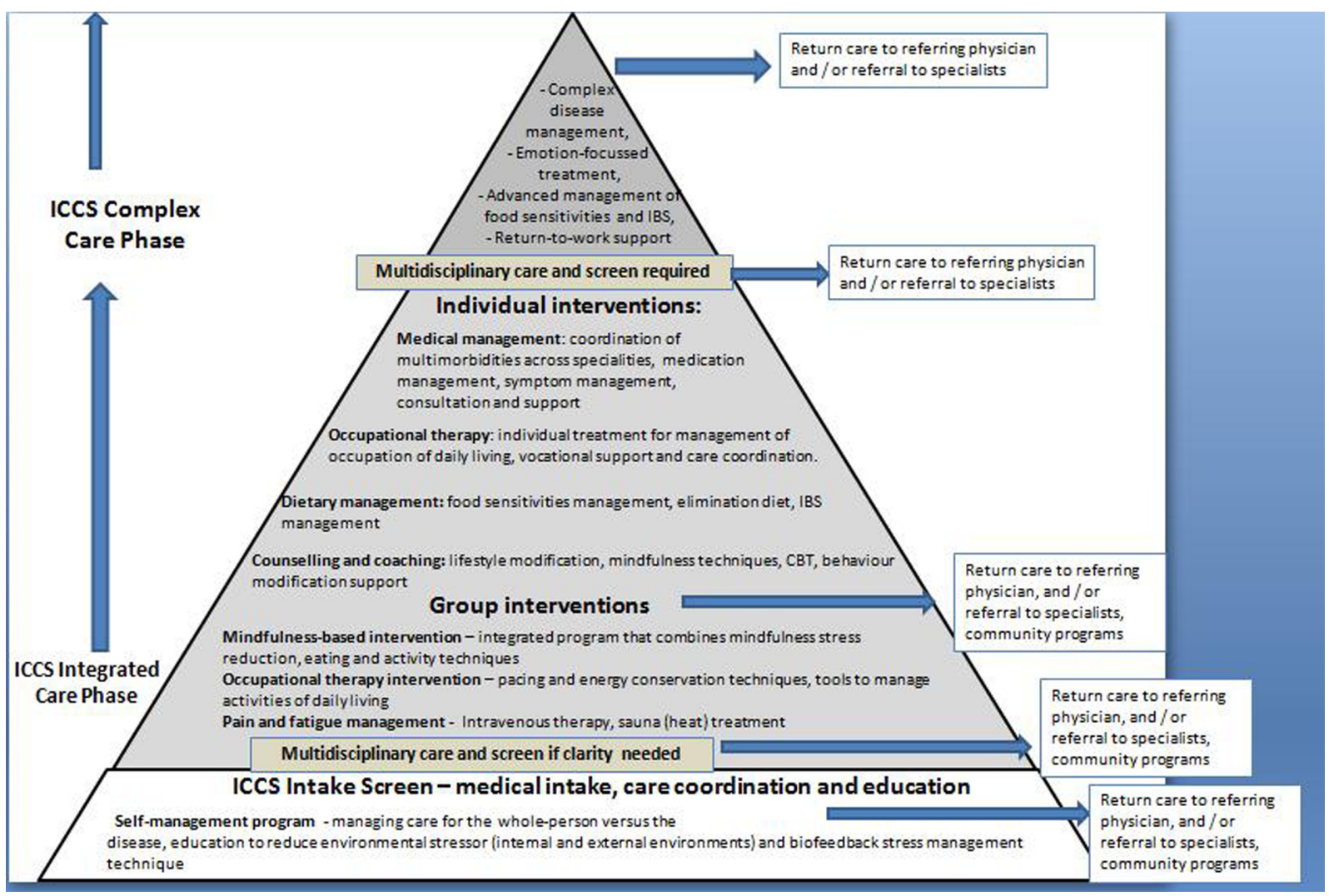

Figure 3 Integrated care modules.

\section{Outcome measures}

Outcome parameters must measure meaningful health outcomes of relevance and importance to individuals with multimorbidity. They should enable evaluation of patient perspectives of their own health and the care received. The global objective of the revised care model is to enable shifts in functional health and quality of life. The outcomes selected include the COPM ${ }^{49}$ PACIC, ${ }^{50}$ and a comprehensive questionnaire specifically validated for multiple chemical sensitivity which reviews the severity of symptoms according to organ system, akin to the Cumulative Illness Rating Scale. ${ }^{51}$ COPM and symptom questionnaire are administered before and after intervention, and the PACIC is administered at transition.

\section{Pilot results}

Changes in functional health and symptom management were evaluated in a small group of patients $(n=20)$ comprising
15 women and five men of mean age $42 \pm 5.4$ years who underwent intervention as part of this novel model of care. The average duration of treatment was approximately 6 months. The mean number of chronic conditions in this pilot group was $3.75 \pm 1.2$.

Table 1 shows the PACIC results captured during the transition phase of care. Most scores for the subscales of the PACIC were in the higher range, with mean values above a score of 4 for delivery system/practice design, goal setting/ tailoring, and problem solving/contextual. Follow-up/ coordination received a lower rating compared with the rest, but was still ranging over the half-way point in scoring.

COPM scores before and after intervention are shown in Table 2. The patients had scores $4-5$ points higher in their self-identified performance problems. The top categories identified included exercise, work, energy levels, housework, and preparation of meals. Satisfaction scores on the COPM

Table I Patient Assessment of Chronic Illness Care questionnaire scores*

\begin{tabular}{llllll}
\hline $\begin{array}{l}\text { Group } \\
(\mathbf{n}=\mathbf{2 0})\end{array}$ & Patient activation & $\begin{array}{l}\text { Delivery system/ } \\
\text { practice design }\end{array}$ & $\begin{array}{l}\text { Goal setting/ } \\
\text { tailoring }\end{array}$ & $\begin{array}{l}\text { Problem solving/ } \\
\text { contextual }\end{array}$ & $\begin{array}{l}\text { Follow-up/ } \\
\text { coordination }\end{array}$ \\
\hline Mean \pm SD & $3.8 \pm 1.1$ & $4.2 \pm 1.2$ & $4.3 \pm 0.9$ & $4.4 \pm 1.3$ & $3.1 \pm 1.1$ \\
\hline
\end{tabular}

Notes: *Scored as: I-none of the time; 5 -all of the time. 
Table 2 Canadian Occupational Performance Measure scores*

\begin{tabular}{lll}
\hline $\begin{array}{l}\text { Pilot group } \\
(\mathbf{n}=\mathbf{2 0})\end{array}$ & $\begin{array}{l}\text { COPM performance } \\
\text { Mean } \pm \mathbf{~ S D ~}\end{array}$ & $\begin{array}{l}\text { COPM satisfaction } \\
\text { Mean } \pm \text { SD }\end{array}$ \\
\hline Pretest & $3.5 \pm 2.5$ & $3.75 \pm 1.5$ \\
Post-test & $7.35 \pm 2.2$ & $8.5 \pm 1.8$ \\
Difference & $3.55 \pm 1.1$ & $4.75 \pm 1.3$ \\
$P$ value & $<0.001$ & $<0.001$ \\
\hline
\end{tabular}

Notes: *Scored as: I, low ability or satisfaction; 10, high ability or satisfaction. Abbreviations: COPM, Canadian Occupational Performance Measure; SD, standard deviation.

also increased after intervention, and were almost twice the scores beforehand. Symptom scores showed significant shifts after intervention in terms of overall perception of health and in fatigue scores. Ratings for overall health, fatigue, and pain are shown in Table 3.

\section{Discussion}

This paper describes an integrated model of care to address the challenges of multimorbidity. There is limited research on effective management strategies to address the financial and health impact of multimorbidity. The growing evidence of multimorbidity in younger patients is also of concern. There is a clear need to develop effective care models that can enhance functional health and reduce the burden of disability in this complex patient population.

A review of the literature identified certain key elements of relevance to the management of multimorbidities. The global needs of affected patients appear to include integration of care to address their constellation of physical, functional, and psychosocial problems. This paper presents an integrated care model developed to address the challenges of multimorbidity in a treatment facility for complex chronic conditions. The proposed care model incorporates certain novel elements of care management identified in the literature, including indepth assessment of multiple diagnoses and a multidimensional symptom profile, integration of care

Table 3 Symptom scores

\begin{tabular}{llll}
\hline $\begin{array}{l}\text { Pilot group } \\
(\mathbf{n}=\mathbf{2 0})\end{array}$ & $\begin{array}{l}\text { Pre } \\
\text { mean } \pm \text { SD }\end{array}$ & $\begin{array}{l}\text { Post } \\
\text { mean } \pm \text { SD }\end{array}$ & P value \\
\hline $\begin{array}{l}\text { Rating of health } \\
\text { since onset of illness } \\
\text { (I, worst; 7, best possible) }\end{array}$ & $2.62 \pm 1.2$ & $6.2 \pm 2$ & $<0.000$ I \\
$\begin{array}{l}\text { Fatigue } \\
\text { (I, no symptoms; }\end{array}$ & $7.3 \pm 2.4$ & $2.8 \pm \mathrm{I} . \mathrm{I}$ & $<0.000$ I \\
$\begin{array}{l}\text { I2, worst possible) } \\
\text { Pain }\end{array}$ & & & \\
(I, no symptoms; & $6.4 \pm 2.5$ & $4.5 \pm 1.3$ & 0.06 \\
I2, worst possible) & & & \\
\hline
\end{tabular}

Abbreviation: SD, standard deviation. needs, coordination of treatment at the care, health system, and community levels, and providing care to help the person without focusing on the disease. The overall goal of care is to help the individual improve their functional health and quality of life. Education modules that impart skills and coping strategies to enhance self-management and facilitate healthy behavior are also an integral aspect of this type of care delivery.

The results of this pilot evaluation, despite the small sample size, are promising, and are a preliminary step towards the design of a larger randomized controlled trial to understand better the effectiveness of this novel care model for challenging and complex conditions. Further research is also required to determine if the cost impact to the system from managing patients in this manner can outweigh the costs of just being managed by their family physician versus engagement of an integrated care team.

\section{Disclosure}

The authors declare that they have no conflict of interest in this work.

\section{References}

1. Mercer S, Smith S, Wyke S, O'Dowd T, Watt G. Multimorbidity in primary care: developing the research agenda. Fam Pract. 2009;26: 79-80.

2. Uijen AA, Lisdonk EH. Multimorbidity in primary care: prevalence and trend over the last 20 years. Eur J Gen Pract. 2008;1:28-32.

3. Schram MT, Frijters D, Lisdonk EH, et al. Setting and registry characteristics affect the prevalence and nature of multimorbidity in the elderly. J Clin Epidemiol. 2008;61:1104-1112.

4. Marengoni A, Winblad B, Karp A, Fratiglioni L. Prevalence of chronic diseases and multimorbidity among the elderly population in Sweden. Am J Public Health. 2008;98:1198-1200.

5. Fuchs Z, Blumstein T, Novikov I, et al. Morbidity, comorbidity, and their association with disability among community-dwelling oldest-old in Israel. J Gerontol A Biol Sci Med Sci. 1998;53:447-455.

6. Britt HC, Harrison CM, Miller GC, Knox SA. Prevalence and patterns of multimorbidity in Australia. Med J Aust. 2008;189:72-77.

7. Wolff JL, Starfield B, Anderson G. Prevalence, expenditures, and complications of multiple chronic conditions in the elderly. Arch Intern Med. 2002;162:2269-2276.

8. Akker M, Buntinx F, Metsemakers JF, Roos S, Knottnerus JA. Multimorbidity in general practice: prevalence, incidence, and determinants of co-occurring chronic and recurrent diseases. J Clin Epidemiol. 1998;51:367-375.

9. Metsemakers JF, Hoppener P, Knottnerus JA, Kocken RJ, Limonard CB. Computerized health information in the Netherlands: a registration network of family practices. Br J Gen Pract. 1992;42:102-106.

10. Daveluy C, Pica L, Audet N, Courtemanche R, Lapointe F. In: Health and Social Survey 1998. 2nd ed. Québec, Canada: Institut de la Statistique du Québec; 2000.

11. Rapoport J, Jacobs P, Bell NR, Klarenbach S. Refining the measurement of the economic burden of chronic diseases in Canada. Chronic Dis Can. 2004;25:13-21.

12. Fortin M, Bravo G, Hudon C, Vanasse A, Lapointe L. Prevalence of multimorbidity among adults seen in family practice. Ann Fam Med. $2005 ; 3: 223-228$. 
13. Parekh AK, Barton MB. The challenge of multiple comorbidity for the US health care system. JAMA. 2010;303:1303-1304.

14. Beasley J, Hankey T, Erickson R, et al. How many problems do family physicians manage at each encounter? A WReN study. Ann Fam Med. 2004;2:405-410.

15. Guralnik JM. Assessing the impact of comorbidity in the older population. Ann Epidemiol. 1996;6:376-380.

16. Bayliss E, Edwards A, Steiner J, Main D. Processes of care desired by elderly patients with multimorbidities. Fam Pract. 2008;25:287-293.

17. Boyd CM, Darer J, Boult C, Fried LP, Boult L, Wu AW. Clinical practice guidelines and quality of care for older patients with multiple comorbid diseases: implications for pay for performance. JAMA. 2006; 294:716-724.

18. Taylor A, Price K, Gill T, Adams R, et al. Multimorbidity - not just an older person's issue. Results from an Australian biomedical study. $B M C$ Public Health. 2010;10:718.

19. Sevick MA, Trauth JM, Ling BS, et al. Patients with complex chronic diseases: perspectives on supporting self-management. J Gen Intern Med. 2007;22:438-444.

20. Noel P, Parchman M, Williams J, et al. The challenges of multimorbidity from the patient perspective. J Gen Intern Med. 2007;22:419-424.

21. Fortin M, Bravo G, Hudon C, et al. Relationship between multimorbidity and health-related quality of life of patients in primary care. Qual Life Res. 2006;15:83-91.

22. Bayliss EA, Steiner JF, Fernald DH, Crane LA, Main DS. Descriptions of barriers to self-care by persons with comorbid chronic diseases. Ann Fam Med. 2003;1:15-21.

23. Glynn LG, Valderas JM, Healy P, et al. The prevalence of multimorbidity in primary care and its effect on health care utilization and cost. J Fam Pract. 2011;28:516-523.

24. Charlson M, Charlson RE, Briggs W, Hollenberg J. Can disease management target patients most likely to generate high costs? The impact of comorbidity. J Gen Intern Med. 2007;22:464-469.

25. Wagner EH. Chronic disease management: what will it take to improve care for chronic illness? Eff Clin Pract. 1998;1:2-4.

26. Tsai AC, Morton SC, Mangione CM, Keeler EB. A meta-analysis of interventions to improve care for chronic illnesses. Am J Manage Care. $2005 ; 11: 478-488$

27. Siminerio L, Zgibor J, Solano F. Implementing the chronic care model for improvements in Diabetes practice and outcomes in primary care: the University of Pittsburgh Medical Center experience. Clin Diabetes. 2004;22:54-58

28. Corser WD. An investigation of patient outcomes related to comorbidity and interdisciplinary hospital discharge planning. Outcomes Manag. 2004;8:45-51.

29. Lorig KR, Holman HR. Self-management education: Definition, outcomes, and mechanisms. Ann Behav Med. 2002;26:1-7.

30. Pomerantz JI, Toney SD, Hill ZJ. Care coaching: an alternative approach to managing comorbid depression. Prof Case Manag. 2010; 15:137-142

31. Parchman ML, Noel PH, Lee S. Primary care attributes, health care system hassles, and chronic illness. Med Care. 2005;43:1123-1129.

32. Fortin M, Hudon C, Haggerty J, Akker M, Almirall J. Prevalence estimates of multimorbidity: a comparative study of two sources. BMC Health Serv Res. 2005;10:111.
33. Yunus MB. Central sensitivity syndromes: a new paradigm and group nosology for fibromyalgia and overlapping conditions, and related issue of disease versus illness. Semin Arthritis Rheum. 2008;37: 339-352.

34. Leatt P, Pink G, Guerriere M. Towards a Canadian model of integrated healthcare. Healthc Pap. 2000;1:13-35.

35. Kodner DL, Spreeuwenberg C. Integrated care: meaning, logic, applications, and implications - a discussion paper. Int J Integr Care. 2002;2:e12.

36. Bridgepoint Community Rehabilitation. Bridgepoint Health. Toronto, Canada: Internal Statistics Report; 2006.

37. Anderson G, Horvath J, Herbert R, Ridgeway K, Pavlovich W, Harjai G, et al. Chronic Conditions: Making the Case for Ongoing Care. Partnership for Solutions, Johns Hopkins University, for the Robert Wood Johnson Foundation; 2002. http://www.rwjf.org/files/research/chronicbook2002.pdf. Accessed May 23, 2012.

38. Crawford G, Price S. Team working: palliative care as a model for interdisciplinary practice. Med J Aust. 2003;179:S32-S34.

39. Stange KC. The problem of fragmentation and need for integrative solutions. Ann Fam Med. 2009;7:100-103.

40. Bodenheimer T. Disease management - promises and pitfalls. $N$ Engl J Med. 1999;340:1202-1205.

41. Grumbach K. Chronic illness, comorbidities and the needs for medical generalism. Ann Fam Med. 2003;1:4-7.

42. Kirby SE, Chong JL, Frances M, et al. Sharing or shuffling: realities of chronic disease care in general practice. Med J Aust. 2008;189:77.

43. Antonovsky A. The salutogenic model as a theory to guide health promotion. Health Promot Int. 1996;11:11-18.

44. Lorig KR, Sobel DS, Stewart AL, et al. Evidence suggesting that a chronic disease self-management program can improve health status while reducing hospitalization: a randomized trial. Med Care. 1999;37: $5-14$.

45. Hutchinson TA, Hutchinson N, Arnaert A. Whole person care: encompassing the two faces of medicine. CMAJ. 2009;180:845-846.

46. Bartha L, Baumzweiger W, Buscher DS, et al. Multiple chemical sensitivity: a 1999 consensus. Arch Environ Health. 1999;54:147-149.

47. Sampalli T, Shepherd M, Duffy J. A patient profile ontology in the heterogeneous domain of complex and chronic health conditions. Presented at the 44th Hawaii International Conference on System Sciences, Kauai, HI; January 4-7, 2011.

48. Fox R, Sampalli T, Fox J. A proposed model of care management for complex chronic conditions based on the multidisciplinary care management of patients with multiple chemical sensitivity. In: Health Management. Rijeka, Croatia: Sciyo; 2010.

49. Law M, Baptiste S, McColl M, Opzoomer A, Polatajko H, Pollock N. The Canadian occupational performance measure: an outcome measure for occupational therapy. Can J Occup Ther. 1990 Apr;57(2): $82-87$.

50. Bonomi AE, Wagner EH, Glasgow RE, Von Korff M. Assessment of Chronic Illness Care (ACIC): a practical tool to measure quality improvement. Health Serv Res. 2002;37:791-820.

51. Fox RA, Sampalli F, Fox J. Measuring health outcomes of a multidisciplinary care approach in individuals with chronic environmental conditions using and abbreviated symptoms questionnaire. J Multidiscipl Healthc. 2008;1:97-104.
Patient Preference and Adherence

\section{Publish your work in this journal}

Patient Preference and Adherence is an international, peer-reviewed, open access journal focusing on the growing importance of patient preference and adherence throughout the therapeutic continuum. Patient satisfaction, acceptability, quality of life, compliance, persistence and their role in developing new therapeutic modalities and compounds to

\section{Dovepress}

optimize clinical outcomes for existing disease states are major areas of interest. This journal has been accepted for indexing on PubMed Central. The manuscript management system is completely online and includes a very quick and fair peer-review system. Visit http://www.dovepress.com/ testimonials.php to read real quotes from published authors. 